\title{
A Technique for Improving Telecommunications Planning Based on Indices of Growth
}

\author{
Thomas Kokumo Yesufu, Anthony Olutope Fakeye \\ Department of Electronic and Electrical Engineering, Obafemi Awolowo University, Ile-Ife, Nigeria
}

Email address:

thomas_yesufu@yahoo.com (T. K. Yesufu), anthonyolutope@gmail.com (A. O. Fakeye)

To cite this article:

Thomas Kokumo Yesufu, Anthony Olutope Fakeye. A Technique for Improving Telecommunications Planning Based on Indices of Growth. Communications. Vol. 3, No. 2, 2015, pp. 35-41. doi: 10.11648/j.com.20150302.12

\begin{abstract}
Subscribers' indices of growth are essential for planning and ensuring the rapid pursuit of best practices by telecommunication systems in Nigeria. Based on network principles and the established process of telecommunications planning, a questionnaire was developed and administered to 300 stakeholders that were randomly selected from existing subscriber communities across Nigeria. Subsequently, a Java software application for the analysis and planning of telecommunication systems was developed using Netbeans Integrated Design Environment (IDE) for its Rapid Application Development (RAD). It was found that Nigerian telecommunication planning fell below expectations despite the high teledensity in Nigeria, and had $60 \%$ of the necessary user participation, $49 \%$ degree of communication, and $63 \%$ of demanddriven services. Subsequently, a mobile application software system was developed such that the participation of subscribers in the planning process was enlisted via a short message service (SMS) that uses a typical SMS delivery system for sorting out spurious messages. By continuously linking the planning of telecommunications to subscribers' indices of growth, the software would improve reliability, effectively shorten the feedback loop for timely and accurate decision-making, reveal the magnitude of acceptance of telecommunication services, and thereby bring about seamless network integration, technologically and on the applications and service levels.
\end{abstract}

Keywords: Telecommunication Planning, Feedback, Network Reliability, Decision Support Systems, Quality of Service

\section{Introduction}

Telecommunications is the engine of economic growth with which all peoples can get connected seamlessly in order to become a "global village". This scenario makes telecommunication a current national priority both in terms of sustaining the rapid growth of subscribers as well as improving on the existing telecommunication systems (e.g., NCC, 2011; ITU, 2011). Accordingly, a modern telecommunication infrastructure is not only important for domestic growth but also needed to connect domestic market of commodities as well as credit with international commodity and financial markets, this would develop the smooth flow of foreign investment, positive value of net exports, increase the value addition in GDP of an economy etc.

With the advancement of telecommunication services, a new market mechanism, low cost structure and expanded value chain of firms is possible. On the other hand in developing countries, the average price of agricultural commodities is higher in other areas than in the areas where there are no facilities to communicate (Bayes et al, 1999). As the telecommunication capabilities of a country evolve the relevant statistical measures appropriate to assessing national performance change. No single measure is entirely satisfactory in gauging performance. In addition researchers and policy makers invariably face difficulties in finding uniform data. Problems in this area can range from definitional differences to a lack of uniform data collection and management (Patridge, 1992).

Today's telecommunication industry in Nigeria is focusing on a way to improve their products and services as well as sustaining the growth of subscribers (Adegbemi et al., 2012). In view of this, most telecommunications service providers are taking a critical look at their business intelligence through network-inspired planning. Access to information obviously marks the beginning of a good telecommunication plan that focuses on sustainable 
economic development, improved quality of life and the attendant reduction of risks in human activities and development.

A telecommunication service is expected to grow in demand, increase provider-user interaction and absorb new streams of innovations whilst focusing on the required depth of impact and future developments. There is no gainsaying the fact that this expectation relies heavily on telecommunication planning, which includes the collection and analysis of suitable data for timely and accurate decision-making. Planning relies heavily on available data for analysis and decision making. The current trend indicates that telecommunication planning is mostly based on theoretical facts, assumed view of "experts", etc. Telecommunication planning involves processes, procedures, framework and guidelines that translate into action(s). This approach to telecommunication planning can therefore be viewed as a set of tasks required for enhancing appropriate decisions for an effective action plan. In view of this, a low teledensity, inadequate quality of service, fraudulent messaging, questionable subscriber participation and provider/subscriber communications are some of the consequences of inadequate planning. The problems of low tele-density, lack or minimal services suited for local socio economic activities, questionable services performance and minimal/absence of user centric planning approach inspired the need to develop an improved technique. Consequently, that will make the planning of telecommunication systems to fulfill the necessary and sufficient technological requirements such as the physical connectivity between the operators and the subscribers, the procedures for reliable transfer of information and the quality of service. This work will address these consequences, and subsequently evaluate the indices of growth in a telecommunication system and then develop a method for planning a mobile telecommunication system, which will however be benchmarked with the existing methods for planning telecommunication systems.

\section{Theoretical Development}

The Nigerian telecoms market offers a clear and exciting opportunity for many telecom operators. This market is highly deregulated with the NCC licensing a wide variety of telecoms operators. This market has moved from zero to hero in just under few years and is now considered a leading opportunity for both telecom operators and equipment suppliers. The eight steps of the structured planning process are illustrated in the Fig. 1. This solution, with an Implementation Plan, must be presented to the organization's managers for decision making (Pietrasiewicz, 2000).

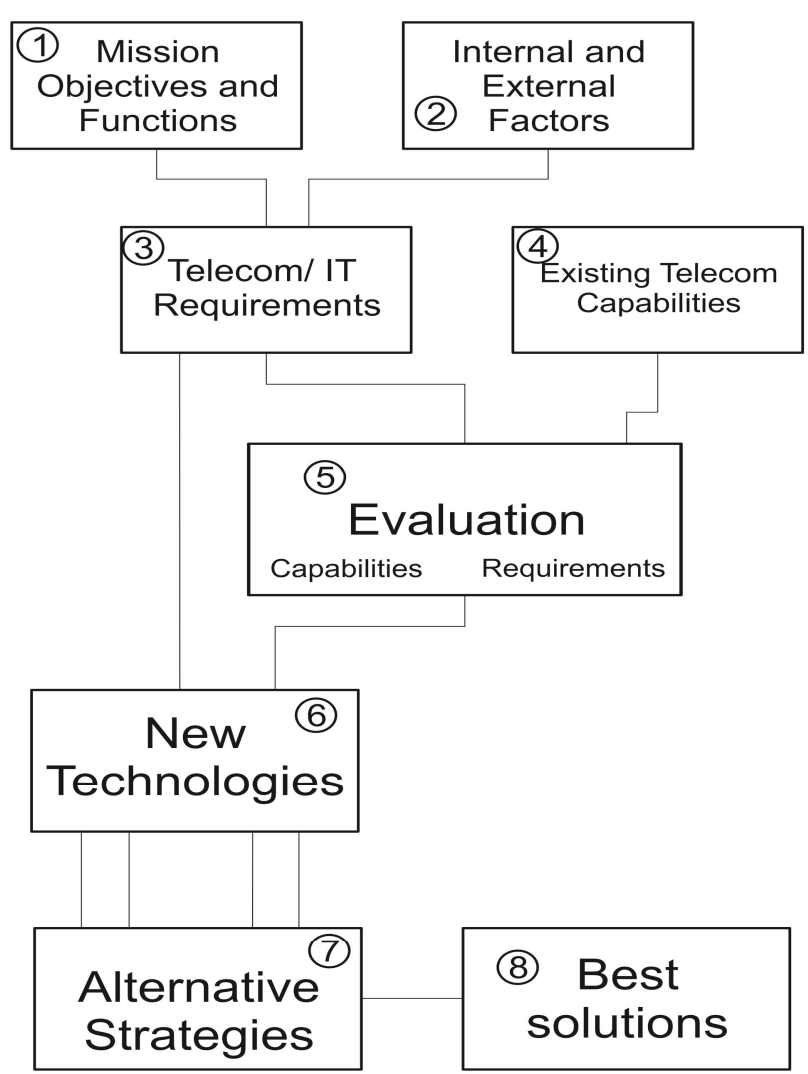

Fig. 1. Telecom/IT planning steps adapted from Pietrasiewicz (2000).

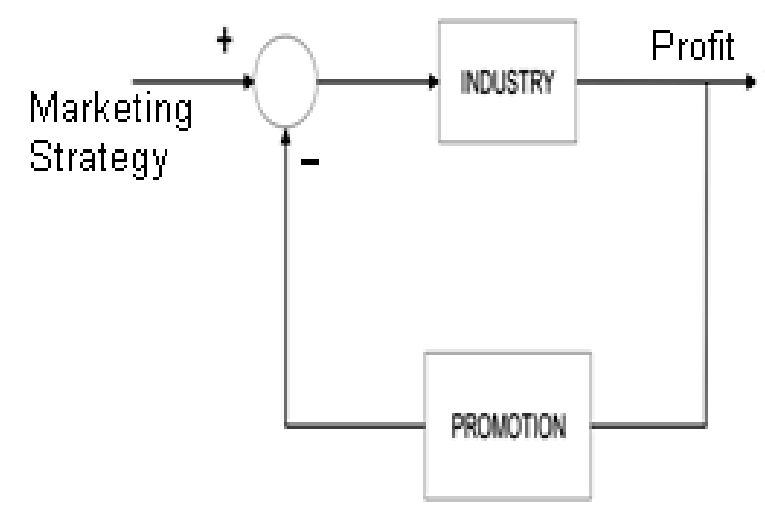

Fig. 2. A block diagram of the business model.

The present ICT industry indicates that mobile services and applications are going to change radically in the future. The future evolution of mobile applications and services means seamless integration, both technologically and on the applications and service level, towards more attractive solutions for users. The attractiveness of mobile applications and services in the future relies heavily on comprehensive fulfillment of user needs. The competitive situation in telecoms is going to change in the countries where the mobile markets are maturing and the competition will make the traditional business models of mobility less attractive. Companies need to seek turnkeys to new sustainable business models, since many of the models in 
use will become obsolete by focusing on a profit-based feedback on the industry's promotion (Fig. 2). At the same time, telecom companies' interests in integrating users and their needs more tightly in the development processes have increased by focusing on a growth-based feedback on the industry's acceptability and reliability. Fig. 3 shows that new business opportunities are in the area of integrated mobile application and service development, which takes users' overall needs more closely into account (Edelmann and Koivuneimi 2004; and Kunz and Black, 1999).

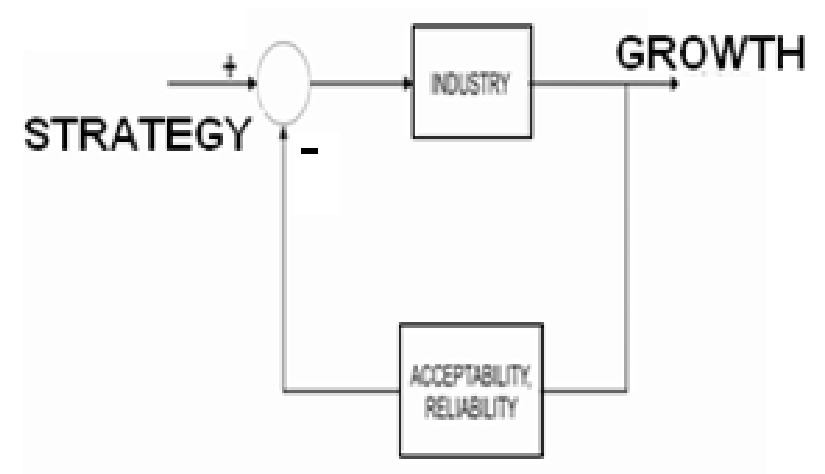

Fig. 3. New opportunities' development model.

Reliability is the ability of an item to perform a function acceptable to the user without failure under stated conditions for a stated period. Telecommunication system planning is concerned with the design and maintenance of large network at a reasonable cost in order to deliver high capacity and speed. In telecommunication systems, the network design problem is challenging engineering and a mathematical one, even when all the sites behave in the mode for which the system is designed, all links are in the mode for which the network is designed and all links provide the level of service expected. The concept of reliability depicts the probability of a system to have an expected performance over a time interval, so the reliability of a system depends on its configuration and the reliability of its components. In real life, however, through human faults, design faults, operational faults, environmental factors, or random wear out, sites and links do not always function correctly. The telecommunication planner must therefore address the reliability issue (Colbourn, 2009). The reason for all these is to establish a feedback that would make planning approaches to yield value added services and also impact positively on the environment.

Connectivity links a provider to a node, and from there, possibly, through other nodes to some final end-user (subscriber) destination with which the initiating end-user wants to communicate. There would seem to be two interpretations of this definition. First, the equipment, both switching and transmission facilities, are available to set up a path from, say, Point A to Point B; assuming A and B to be user end-points. The second interpretation would be that not only are the circuits available but that they are connected and ready to pass information or are in the information passing mode. At this juncture, the end-users are assumed to be telephone users, and the path that is set up may be for speech, text, video, data, etc. Fig. 4 describes a flow diagram of a planner (P) establishing a link between a subscriber (A) and a provider (B).
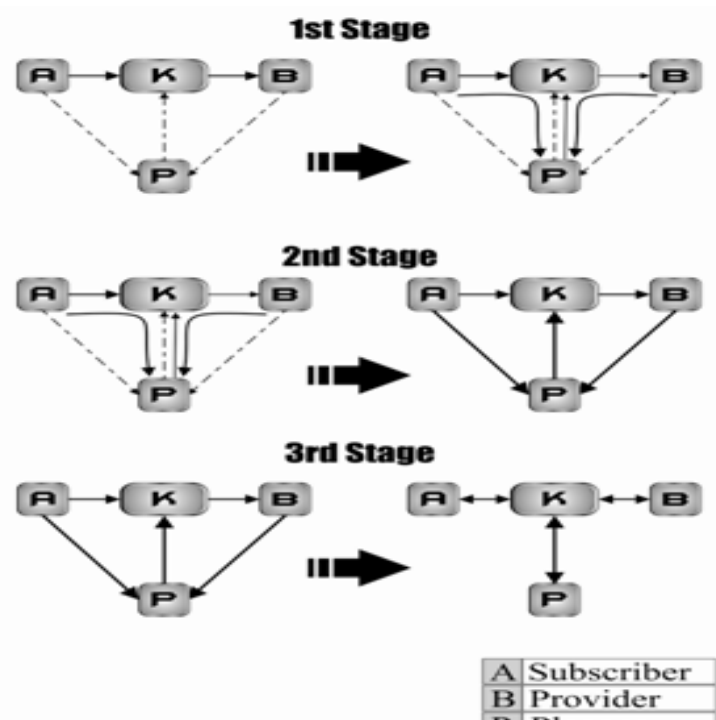

\begin{tabular}{|l|l|}
\hline B & Provider \\
\hline P & Planner \\
\hline
\end{tabular}

Fig. 4. Stages for integrating planning with online subscriber and provider participation.

It can be deduced that performance of a planning exercise relies heavily on the likely unpredictable decision maker(s), even though the actions contained in a plan are felt and experienced. Since the decision makers are the key players $(\mathrm{K})$ that agreed to implement the action plan, the task of easier and good decision making is a major approach to improving planning and this can be indicated with the following indices of growth:

\subsection{Participation}

This generally means having all involved to be represented in the decision making process. This allowed issues to be considered from different points of view but with the knowledge of parties involved to serve as a guide to a concise and effective solution. Since, expectedly, any decision taken without the contribution of involved parties will not reflect a truly acceptable solution.

\subsection{Demand-Driven}

This depicts that the felt effect of decision plays a lot in evaluating planned actions as actions which satisfies the desirable environment in all its ramifications will undoubtedly be considered adequate or vice versa. However, for such desirable acceptance, it is most often demand driven. Therefore, performance will be considered based on the yearnings of the patrons of telecommunication services.

\subsection{Service Quality}

The performance of any telecommunication system can be verified based on its service quality. Service, on the other 
hand, is generally used to describe something offered to the end-users of any network such as end-to-end communication or client-server applications. If a network is inaccessible, the service is clearly questionable. Different people see quality of service as different concepts because various and ambiguous quality of service problems exist. The users of a network service have the tendency of judging the quality of service based on the frequency of failures of the network more than its overall success in delivering information in a consistent and reliable manner. The ambiguity within the quality of service yields different possible solutions to various problems, which leaves somewhat of schism in the networking industry on the issue of quality of service. Quality of service, as perceived by customers/subscribers, is actually the level of satisfaction derived from using a certain telecommunication network. As such, a very well planned system will most likely have as its result a widely acceptable service quality and a badly planned system will most likely be providing unsatisfactory service quality.

\subsection{Communication}

The most effective technique for resolving issues is communications. Therefore, for clearer understanding of issues before decision makers without prejudice and for better understanding of telecommunications environment, a communication platform must be in place.

\section{Experimental Procedure}

Fig. 3 informed the use of the field survey in this paper to determine the knowledge, practice and results of telecommunication planning in Nigeria. This involved sampling the opinion of telecommunication users and practitioners. Data collection for the execution of the survey was carried out through the administration of a structured questionnaire to 300 respondents connected with the activities of telecommunication organizations in order to develop an improved technique for planning a telecommunication system.

The structured questions employed centered on the identified performance indicators of telecommunications networks. The questions of the survey were aimed at extracting information: on the mentioned performance indicators from existing systems as shown in Fig. 5. This perspective will attempt to evaluate separate platforms presented by existing systems for observing the environment, and also how effective are these platforms, the degree of attention paid to subscribers' participation and levels of reliability. The questionnaire was randomly administered to the six geo-political zones in the country. The targeted audience for the circulation was primarily subscribers and providers of telecommunication services in Nigeria. The states visited were Osun, Lagos, Kastina, Enugu, Anambra, Federal Capital Territory Kano, Bayelsa, Delta and Benue. A breakdown of the results from the survey carried out were tabulated using descriptive statistics to cover Participation, Service Quality, Demand-Driven, and Degree of
Communication, which have been identified as the benchmarks for existing planning techniques.

The responses obtained from the survey, as against the performance indicators shown in Fig. 5, created a pathway for software development. The software for an SMS-based participatory planning technique with anti-spamming capability was developed using Netbeans IDE (integrated Design environment) for its RAD (Rapid Application Development) feature, which assists in quick software development. In addition, the use of Java Development Kit (JDK) brings about ease in the deployment of these software solutions.

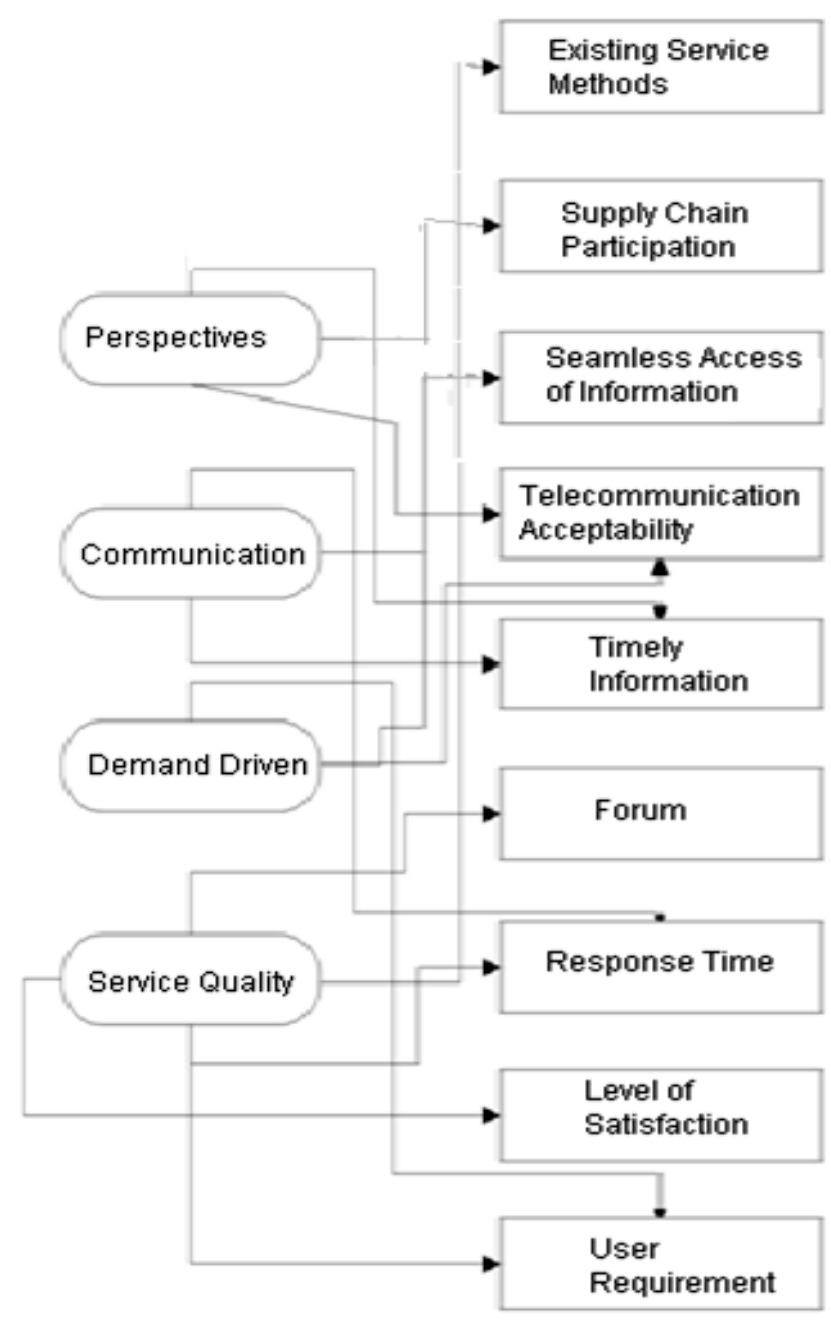

Fig. 5. Perspectives against performance indicators.

\section{Results and Discussion}

The technique applied for this analysis is based on descriptive analysis in which the votes of respondents were counted and the percentage of votes against a performance indicator was calculated based on votes against number of circulated questionnaire. In all, 200 (two hundred) respondents were sampled. However, results from the questionnaire of each respondent were classified based on performance indicators i.e. each performance indicator has a 
$100 \%$ (hundred percent) score for the total expected response while the actual response depicts the factual score from the environment in percentage. Assertions were made based on the magnitude of scores percentage of the respondents.

From the data collected and analyzed, Tables $1-4$ were created. In Table 1, it is observed that telecommunication organizations' planning activities lacked the required participation of all stakeholders. Table 2 shows that the subscriber services were of low quality. Furthermore, Table 3 revealed that most of the services provided were not demand-driven. With this repine, it is clear that communication exists between providers and subscribers but with a high rate of non-reliance on such platforms; hence, the degree of communication is questionable as shown in Table 4.

Table 1. Participation.

\begin{tabular}{lll}
\hline S/N & ACTIVITIES & RESPONDENTS (\%) \\
\hline 1 & $\begin{array}{l}\text { Claimed indirect or direct } \\
\text { involvement in planning } \\
\text { Interest are not particularly }\end{array}$ & 20 \\
2 & represented & 35 \\
3 & Interest particularly represented & 15 \\
4 & No involvement in planning & 26 \\
5 & Indecisive & 4 \\
TOTAL & & 100 \\
\hline
\end{tabular}

Table 2. Service quality.

\begin{tabular}{lll}
\hline S/N & ACTIVITIES & RESPONDENTS (\%) \\
\hline 1 & $\begin{array}{l}\text { Responded to unacceptable service } \\
\text { downtime }\end{array}$ & 63 \\
2 & Responded to Crosstalk & 10 \\
3 & Responded to High Tariffs & 6 \\
4 & Responded to indifferent & 12 \\
5 & Responded to satisfactory services & 9 \\
TOTAL & & 100 \\
\hline
\end{tabular}

Table 3. Demand driven.

\begin{tabular}{lll}
\hline S/N & ACTIVITIES & RESPONDENTS (\%) \\
\hline 1 & Responded to unknown application & 65 \\
2 & Responded to basic services & 25 \\
3 & Responded to understand service & 10 \\
TOTAL & & 100 \\
\hline
\end{tabular}

Table 4. Degree of communication.

\begin{tabular}{lll}
\hline S/N & ACTIVITIES & RESPONDENTS (\%) \\
\hline 1 & Do not rely on forum/for a & 49 \\
2 & Relies on Operator's fora & 21 \\
3 & Relies on Customer Service & 30 \\
TOTAL & & 100 \\
\hline
\end{tabular}

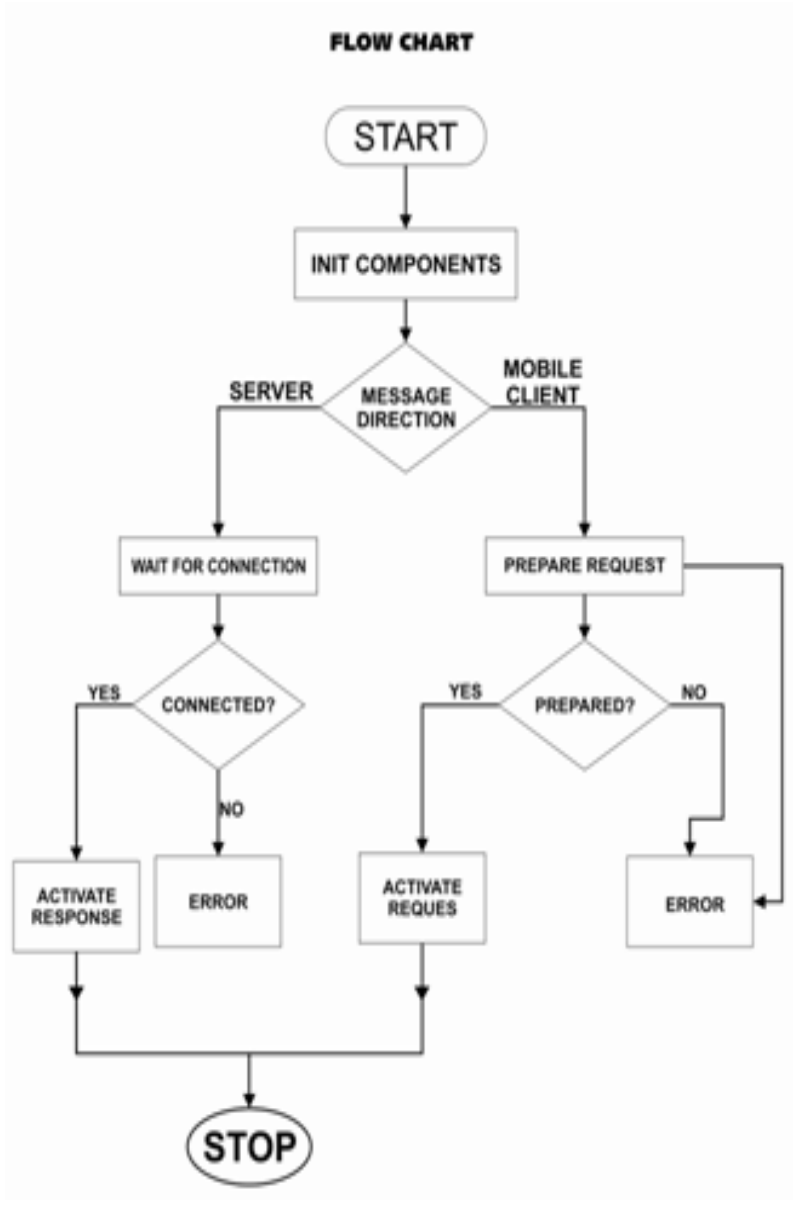

Fig. 6. Flow chart of the participatory technique.

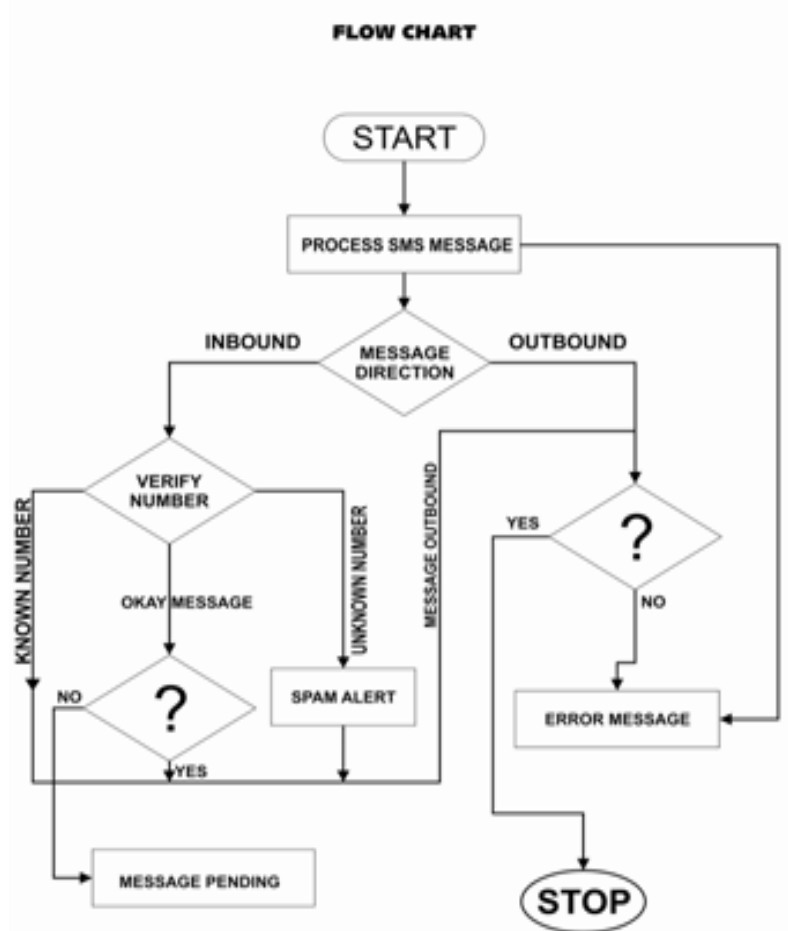

Fig. 7. Flow chart of an Anti-Spam technique. 
A mobile application based on Figs. 3 and 4, and the flow chart in Fig. 6 was developed using Java programming language. This means that the application can be run on phones endorsed for java platform only. In terms of functionality, the application relies a lot on forms i.e. it uses forms for presenting its features to users as a graphical user interface. These features were based on three major tasks, which are Enquiry, Contributions, and Complain. For handling the Enquiry task, the application will connect to an information server for a particular enquiry raised by a user. Subsequently, for complain and contributions of the user, the application forms provide a text input area where users can write their contribution/complain and send. Since the solutions involve a lot of information processing, the solutions will be relying on database server; the server will provide all the information processing support to the Java application, which will plug into the server for information when necessary. The messages goes to a remote server dedicated for such purposes and can be probed for either planned actions or strategic plans as much as possible.

The application is a mobile interface to a server, which handles request from the mobile phone's application. It uses socket communication for establishing a connection between the interface and the Internet server. A socket is a software tool for a secured synchronized communication based on TCP/IP (transmission Control Protocol/Internet Protocol). The application's view is in three phases, which are interface, connection, and storage and explained as follows; For the interface, the application developed used a java platform for mobile application development called Java Toolkit Micro Edition (J2ME).This toolkit relies on java environment to access mobile phone programmable elements like forms, radio buttons etc. These programmable elements were combined and programmed for allowing the applications user to input his/her messages, hence this is conveyed to the storage facility.

Finally, for this mobile application, selecting the complaint option from the starter page navigates to the interface presented in Fig. 5. This allows for texting complaints to the server. This application of allowing participation and communication for impacting demand driven services will be doing so by gathering information from the mobile interface into a database server in which this information can be reviewed and analyzed for strategic decisions. In addition, since it is expectedly toll free and with the ease of accessibility, since it would be installed on phones, it will provide present, most descriptive and most reliable information of the environment that necessary requirements for information used in making effective decisions.

The anti-spamming aspect of the software is basically a server-based application. This application will be integrated with third party software called "Ozeki" SMS Gateway (the flow chart is in Fig. 7). This gateway provides connection to GSM network's SMS service using a modem and a SIM card. This application will be relying on the current SMS gateway architecture that uses a database with two tables for the Inbox and Outbox messages: Inbox for messages coming from an outside source, and Outbox for out-going messages. However, this application is developed for removing spam threats for users of the SMS services. The operations of this application is simply for demonstrating how SMS spam threats can be removed because in actual practice the service will be provided by a GSM network provider, and some components of this application may not be required, thus, making the implementation easy to achieve.

\section{Conclusion}

The paper focused on an approach for carrying out the planning of a telecommunication system based on two different perspectives: the operator's service perspective and the perspective of the environment being serviced. This is because feedback would make planning approaches to yield value added services and also impact on the environment positively. The survey employed assisted in shedding some light on existing approach(es) to telecommunication planning. After analysis, flaws which were inherent in the present setting were noted and used to form the basis for proposing mobile application software that was implemented in order to effectively shorten the feedback loop associated with the developed participatory cum anti-spam technique for improving telecommunication planning. A spam model was also developed with the hope of improving service quality by providing a more robust SMS delivery system targeted at sorting out spurious messages from subscribers.

This paper has also shown that the degree of participation, in terms of users' involvement in planning decisions, is very low. This, in essence, had also impacted on the degree of service provision with the attendant provision of little or no "Demand-Driven" services. In such a situation, it is not unusual finding a form of resistance, which is evident in terms of low or insufficient "communication" and, thereby, a provision of ineffective services. These contributed to the low acceptability of the services and, hence, the need to urgently deploy the developed technique in order to address the potentially harmful low teledensity to the worrying unemployment trend and economic growth in Nigeria.

In summary, the challenge of creating digital opportunities in Nigeria still requires reinforced and concerted efforts on the part of regulatory bodies, the private sector and development partners. Furthermore, by continuously linking the planning of telecommunications to subscribers' indices of growth, the software developed in this paper would improve the reliability of telecommunication networks, effectively shorten the feedback loop basis for decision support, reveal the magnitude of acceptance of telecommunication services, and thereby bring about seamless network integration, technologically and on the applications and service levels. A good telecommunications plan must therefore be attractive, cooperative, interactive and decisive (ACID), as currently being proposed by this paper, in order to neutralize/reduce the implementation risks, which may be due to the growth, moral hazard, reduced participation and adverse selection that follows a typical subscriber base. 


\section{References}

[1] Adegbemi, B.O., Onakoya, A. Sheriffdeen Tella, A. and Adenike Osoba, M.A. (2012): Investment in Telecommunications Infrastructure and Economic Growth in Nigeria: A Multivariate Approach, British Journal of Economics, Management \& Trade, Vol. 2, No. 4, pp. 309-326.

[2] Adeniran, S.A., Raji, T.I. and Yesufu, T.K. (1999): An Approach to Improve Rural Telecommunications in Nigeria, In: Daka, J.S.J., T.J. Afullo, M.O. Adongo, T. Motsoela and A. Obok-Opok: Proceedings of the Third Regional Workshop on Radio Communication in Africa (RADIOAFRICA '99), 25 29 October, 1999, Gaborone, Botswana, pp. $13-16$.

[3] Bayes, A., von Braun, J. and Akhte, R. (1999): Village Pay Phones and Poverty Reduction: Insights from a Grameen Bank Initiative in Bangladesh, Cetre for Development Research, University of Bonn, Germany.

[4] Colbourn, C.J.: Reliability issues in Telecommunications network planning, pdf, pp. 3 - 4.

[5] Edelmann .J. and Koivuneimi, J. (2004): Future Development of Mobile Services and Applications Examined Through the
Real Options Approach, Telektronikk Vol. 2, pp. 48 - 57.

[6] Kunz T. and Black J.P. (1999): An Architecture for Adaptive Mobile Applications, available online at www.ccnga.uwaterloo.ca/publications/pdfs/conf25.pdf, pp. 1 12.

[7] ITU (2011): Least Developed Countries: A Decade of Growth , but Challenges Remain, International Telecommunication (ITU) News, July/August 2011.

[8] NCC (2011): telecommunications business in nigeria: how far? A Speech by the Executive Vice Chairman of the Nigerian Communications Commission (NCC) Dr. Eugene Juwah, at the International Communications Lecture Organized by the Nigeria-Swedish Chamber of Commerce, on Friday, April 8, 2011, at the commerce house, Victoria Island, Lagos.

[9] Patridge, S. (1992): 'Telecommunication Indicators and their Interpretation'; Lessons from Australian Communications: V0I6N0I.

[10] Pietrasiewicz V. J. (2000): Telecommunications and Information Technology Planning: In: Fakeye, A.O. (2012): An M.Sc. Thesis Submitted to the Department of Electronic and Electrical Engineering, Obafemi Awolowo University, IleIfe, Nigeria. 